\title{
Fetal asphyctic preconditioning modulates the acute cytokine response thereby protecting against perinatal asphyxia in neonatal rats
}

Evi Vlassaks ${ }^{1,2}$, Eveline Strackx ${ }^{1,2}$, Johan SH Vles ${ }^{3}$, Maria Nikiforou ${ }^{1,2}$, Pilar Martinez-Martinez ${ }^{2}$, Boris W Kramer ${ }^{1}$ and Antonio WD Gavilanes ${ }^{1 *}$

\begin{abstract}
Background: Perinatal asphyxia (PA) is a major cause of brain damage and neurodevelopmental impairment in infants. Recent investigations have shown that experimental sublethal fetal asphyxia (FA preconditioning) protects against a subsequent more severe asphyctic insult at birth. The molecular mechanisms of this protection have, however, not been elucidated. Evidence implicates that inflammatory cytokines play a protective role in the induction of ischemic tolerance in the adult brain. Accordingly, we hypothesize that FA preconditioning leads to changes in the fetal cytokine response, thereby protecting the newborn against a subsequent asphyctic insult.

Methods: In rats, FA preconditioning was induced at embryonic day 17 by clamping the uterine vasculature for 30 min. At term birth, global PA was induced by placing the uterine horns, containing the pups, in a saline bath for 19 min. We assessed, at different time points after FA and PA, mRNA and protein expression of several cytokines and related receptor mRNA levels in total hemispheres of fetal and neonatal brains. Additionally, we measured pSTAT3/STAT3 levels to investigate cellular responses to these cytokines.

Results: Prenatally, FA induced acute downregulation in IL-1 $\beta$, TNF- $\alpha$ and IL-10 mRNA levels. At 96 h post FA, IL- 6 mRNA and IL-10 protein expression were increased in FA brains compared with controls. Two hours after birth, all proinflammatory cytokines and PSTAT3/STAT3 levels decreased in pups that experienced FA and/or PA.

Interestingly, IL-10 and IL-6 mRNA levels increased after PA. When pups were FA preconditioned, however, IL-10 and IL-6 mRNA levels were comparable to those in controls.

Conclusions: FA leads to prenatal changes in the neuroinflammatory response. This modulation of the cytokine response probably results in the protective inflammatory phenotype seen when combining FA and PA and may have significant implications for preventing post-asphyctic perinatal encephalopathy.
\end{abstract}

Keywords: Asphyxia, Cytokines, Inflammation, Perinatal, Preconditioning

\section{Background}

Perinatal hypoxia/ischemia or asphyxia (PA) is associated with a high mortality rate and causes multiorgan deficits including encephalopathy, leading to permanent structural brain damage [1,2]. Irrespective of the prevalence of PA, there is no effective treatment for term infants having post-asphyctic encephalopathy, except for hypothermia for

\footnotetext{
*Correspondence: danilo.gavilanes@mumc.nl

'Department of Pediatrics Division of Neonatology, Maastricht University Medical Center, School for Oncology and Developmental Biology Maastricht (GROW), Maastricht, AZ 6202, The Netherlands

Full list of author information is available at the end of the article
}

moderate cases [3]. We have shown in a rat model that a brief episode of fetal asphyxia (FA) at embryonic day 17 (E17) lowers the severity of a subsequent more severe global asphyctic insult at term birth (FA preconditioning) [4]. FA preconditioned animals have less apoptosis in different regions of the brain and show improved locomotor function and object memory after PA compared with nonpreconditioned animals $[4,5]$. The molecular mechanisms underlying FA preconditioning have however not been elucidated yet.

Several studies suggest that inflammation has a key role in perinatal brain injury, including cerebral hypoxia/

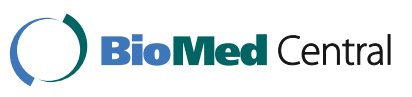


ischemia [6,7]. Inflammatory cells, such as neutrophils and macrophages, but also resident brain cells, such as astrocytes and microglia, have been found to be activated by cerebral ischemia. These cells consequently produce inflammatory mediators, including reactive oxygen species and cytokines [8]. Human data revealed elevated interleukin (IL)-6 and tumor necrosis factor (TNF)- $\alpha$ levels in cerebrospinal fluid (CSF) from newborn infants with asphyctic encephalopathy [9]. Moreover, the concentrations of IL-6, IL-8 and IL-10 have been shown to be upregulated in the sera of asphyxiated neonates compared with those in normal neonates [10]. In experimental stroke models, where they studied the P7 carotid artery ligation model, they also found increased levels and activity of IL-1 $\beta$, IL- 6 and TNF- $\alpha$ several hours to days after the insult $[11,12]$. In contrast, Ashdown and coworkers reported lower IL-1 $\beta$ and TNF- $\alpha$ protein expression and lower IL- 6 mRNA levels in neonatal rat brains $2 \mathrm{~h}$ after global PA [7]. Although special attention is needed concerning the controversies reported between focal and global asphyctic insults, all these experiments indicate that cytokines may modulate asphyctic damage in brain tissue. Moreover, inflammatory cytokines are implicated to be protective in ischemic brain tolerance [13-16]. It has been suggested that preconditioning ameliorates asphyxiainduced brain damage by suppressing the inflammatory response $[13,16]$. No experimental studies, however, have examined the role of cytokines after global FA preconditioning in a perinatal setting. Therefore, we aimed to investigate the inflammatory response that is activated during asphyctic brain damage. In addition, we investigated whether levels of pro- and antiinflammatory cytokines modulate neuroprotection against PA injury. To study this, we used a rat model where two global, instead of focal, asphyctic insults were combined to better reflect the pathology of global asphyctic encephalopathy and multiple organ failure in the human neonate $[17,18]$. We found that FA induces time-dependent cytokine changes, probably resulting in a protective inflammatory phenotype when followed by PA.

\section{Methods}

\section{Animals and tissue processing}

Animal experiments were approved and performed according to the guidelines of the Animal Ethics Board of Maastricht University, The Netherlands. Timed-pregnant Sprague-Dawley rats, obtained from Charles River (France), were housed individually under standard laboratory conditions. Pregnant rats were randomly assigned to an experimental group. Unsexed fetuses and male neonates were used in this study.

For the collection of tissue samples, dams and pups were killed by decapitation at several time points after FA and at different time points after birth $(n=4-5)$ (Figure 1). Total brain hemispheres were collected from the offspring, snap-frozen in liquid nitrogen and preserved at $-80^{\circ} \mathrm{C}$ for further analysis.

\section{FA preconditioning and PA}

The current study used a rat model where two global asphyctic insults were combined. At E17, FA preconditioning was induced by performing a midline laparotomy in pregnant rats. Both uterine horns containing the pups were exposed, and the uterine and ovarian arteries were clamped using four removable clamps. After $30 \mathrm{~min}$, the clamps were removed to allow reperfusion, the uterine horns were placed back intra-abdominally, and the abdominal cavity was closed. The procedures explained above were performed in a controlled environment at $37^{\circ} \mathrm{C}$ and $75 \%$ air humidity.

To assure full-term pregnancy and the physiology of labor, Caesarean section (C-section) was only performed after the vaginal delivery of the first-born pup. Control and FA pups were delivered immediately by $\mathrm{C}$-section. To induce PA, pregnant rats were killed by decapitation to avoid the potential effect of the anesthetic. After hysterectomy, the uterine horns containing the pups were placed in saline $\left(0.9 \% \mathrm{NaCl}, 37^{\circ} \mathrm{C}\right)$ for exactly $19 \mathrm{~min}$. Afterwards, pups exposed to the PA insult were delivered and stimulated manually to breathe in a closed incubator $\left(37^{\circ} \mathrm{C}\right.$ and $75 \%$ air humidity). The umbilical

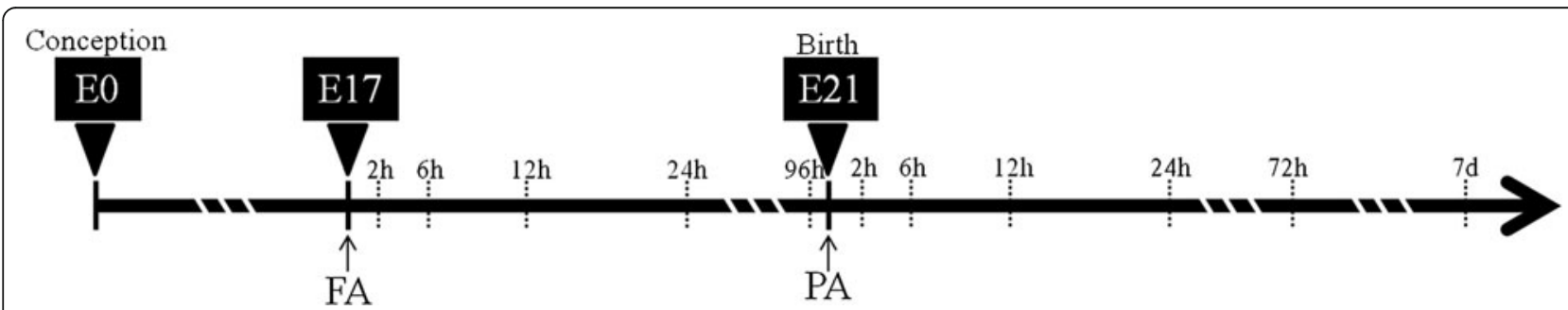

Figure 1 Experimental design. FA was induced at E17 by clamping the uterine vasculature for 30 min. At term birth, global PA was induced by placing the uterine horns containing the pups in a saline bath $\left(37^{\circ} \mathrm{C}\right)$ for $19 \mathrm{~min}$. All animals were delivered by Caesarean section. Pups were killed at five different time points after FA prenatally ( $n=5$ per group per time point) and six different time points postnatally ( $n=4$ per group per time point). $E=$ embryonic day, $F A=$ fetal asphyxia, $P A=$ perinatal asphyxia. 
cords were ligated and cut to separate the pups from their placentas. Pups were randomly cross-fostered with surrogate dams (maximally 12 pups each dam) that had given birth vaginally on the same day.

\section{RNA isolation and RT-PCR}

Total RNA was extracted from frozen brain tissue by homogenization of the samples with Trizol Reagent (Invitrogen, Breda, The Netherlands) according to the manufacturer's guidelines. RIN values were determined using the Agilent 2100 Bioanalyzer (Agilent Technologies, Amstelveen, the Netherlands). All RNA samples had RIN > 8 and were included. Quantity of the RNA was determined with the Nanodrop (ND-1000 spectrophotometer; Thermo Scientific, Wilmington, DE, USA). Reverse transcription was carried out from $1 \mu \mathrm{g}$ total RNA using the Revert Aid First Strand cDNA Synthesis Kit (Fermentas, St. Leon Rot, Germany) according to the manufacturer's instructions. Then $5 \mu \mathrm{l}$ of diluted cDNA (dilution 1:20) was amplified with LightCycler 480 SYBR Green I Master (Roche Applied Science, Almere, The Netherlands) in a final volume of 20 $\mu \mathrm{l}$. The real-time PCR was performed on a LightCycler 480 system (Roche Applied Science; 45 cycles: $20 \mathrm{~s}$ at $95^{\circ} \mathrm{C}, 15 \mathrm{~s}$ at $60^{\circ} \mathrm{C}, 15 \mathrm{~s}$ at $\left.72^{\circ} \mathrm{C}\right)$. Each PCR was carried out in duplicate, and samples negative for RevertAid Reverse Transcriptase were used as negative control. Investigated genes were: IL-1 $\beta$ and IL-1R1 and 2, IL-6 and IL-6R, TNF$\alpha$ and TNFR1/p55 and 2/p75, and IL-10 and IL-10R (Table 1). To standardize for the amount of cDNA, cytokine expressions were compared to the geomean of $\beta$-actin, hypoxanthine-guanine phosphoribosyltransferase (HPRT) and glyceraldehyde 3-phosphate dehydrogenase (GAPDH) (Table 1). Quantification cycle values were extracted with the Lightcycler 480 software (Conversion LC and Linge PCR) and calculated based on the cycle threshold $(\mathrm{Ct})$ values.

\section{Cytometric bead array}

Pro- and antiinflammatory cytokine concentrations in brain homogenates were determined using the BD cytometric bead array (CBA) flex set kit (BD Biosciences, Breda, The Netherlands). The cytokine concentrations in tissue homogenates were calculated from standard curves generated using purified cytokines provided by the manufacturer. Brain pieces were homogenized using a Zymo Research bead beater for $2 \times 20 \mathrm{~s}$ at $6 \mathrm{~m} / \mathrm{s}$ in water yielding a $250 \mathrm{mg} / \mathrm{ml}$ tissue homogenate. The concentration of total protein was measured with the Bradford method. All samples were then incubated with microbeads for each of the cytokines. Analysis for IL-6, IL-10 and TNF $\alpha$ content was performed by flow cytometry according to the manufacturer's directions. Analysis was performed using CBA software, which allows
Table 1 Oligonucleotide primers used for RT-PCR

\begin{tabular}{|c|c|c|}
\hline Primer & $\mathrm{Tm}^{\circ}$ & Sequence $\left(5^{\prime}-3^{\prime}\right)$ \\
\hline HPRT for & 64.1 & TTGCTGGTGAAAAGGACCTC \\
\hline HPRT rev & 64.0 & TCCACTTTCGCTGATGACAC \\
\hline$\beta$-actin for & 64.2 & TTGCTGACAGGATGCAGAAG \\
\hline$\beta$-actin rev & 64.0 & TGATCCACATCTGCTGGAAG \\
\hline GAPDH for & 63.4 & СТСССАТTСТTССАССТTTG \\
\hline GAPDH rev & 63.8 & ATGTAGGCCATGAGGTCCAC \\
\hline IL-1 $\beta$ for & 67.0 & TACCTATGTCTTGCCCGTGGAG \\
\hline IL-1 $\beta$ rev & 67.6 & ATCATCCCACGAGTCACAGAGG \\
\hline TNFa for & 64.0 & TGCCTCAGCCTCTTCTCATT \\
\hline TNFa rev & 63.2 & GGGCTTGTCACTCGAGTTTT \\
\hline IL-6 for & 62.5 & AAAGCCAGAGTCATTCAGAGC \\
\hline IL-6 rev & 63.8 & GAGCATTGGAAGTTGGGGTA \\
\hline IL-10 for & 64.0 & CCTGCTCTTACTGGCTGGAG \\
\hline IL-10 rev & 63.8 & TGTCCAGCTGGTCCTTCTTT \\
\hline IL-1R1 for & 63.7 & TTGTGTTTAAGCTGTTGCCG \\
\hline IL-1R1 rev & 62.4 & GTAACCTCGATGGTATCTTCCC \\
\hline IL-1R2 for & 61.9 & AGCACGTTTATCTCAGTGGC \\
\hline IL-1R2 rev & 65.5 & GTGACTGGATCAAAAATCAGCG \\
\hline TNFR1/p55 for & 61.9 & AGTCTACTGTGCCGATATCCC \\
\hline TNFR1/p55 rev & 64.9 & CTTGACAGGAGCTGAATCCC \\
\hline TNFR2/p75 for & 64.0 & AAATGCAAGCACAGATGCAG \\
\hline TNFR2/p75 rev & 64.3 & CAGCAGACCCAGAGTTGTCA \\
\hline IL-6R for & 63.8 & CTGGTTCCTCTCCTCACCC \\
\hline IL-6R rev & 64.9 & TGTTGCTGTTGTCATTAGGGC \\
\hline IL-10R for & 63.8 & ATTCACCGTGACCAACCTC \\
\hline IL-10R rev & 64.1 & CCAGGATGTGAATGTCATCG \\
\hline
\end{tabular}

the calculation of cytokine concentrations in unknown samples [19].

\section{Immunohistochemistry}

Brain hemispheres of postnatal pups were fixed in Somogyi, snap-frozen with $\mathrm{CO}_{2}$ and cut in 16- $\mu \mathrm{m}$ sagittal sections. Inflammatory cytokine expression was determined by immunohistochemical staining for IL-1 $\beta$, TNF- $\alpha$ IL- 6 and IL-10. After antigen retrieval, endogenous peroxidase activity was blocked by incubation in 3\% hydrogen peroxide. Nonspecific binding sites were blocked with serum. Cytokines were stained with rabbit polyclonal anti-IL1 $\beta$ (Santa Cruz Biotechnology, dilution 1:50), goat polyclonal anti-TNF $\alpha$ (Santa Cruz Biotechnology, dilution 1:200), goat polyclonal anti-IL6 (R\&D Systems, dilution 1:200) and goat polyclonal anti-IL-10 (Santa Cruz Biotechnology, dilution 1:100). Biotinylated polyclonal swine anti-rabbit IgG and anti-goat (DAKO, dilution 1:200/1:500) were applied as secondary antibody. Staining was performed with $\mathrm{DAB}$, and sections were counterstained with cresyl violet. 
Sections were photographed using a Nikon digital camera DMX1200 and ACT-1 v2.63 software from Nikon Corporation.

\section{Western blotting}

Frozen brain tissue was homogenized in CelLytic MT Mammalian Tissue Lysis/Extraction Reagent (Sigma, St-Louis, MO, USA). The samples were then centrifuged at $15,000 \mathrm{~g}$ for $10 \mathrm{~min}$. The protein-containing supernatants were collected, and the concentration of total protein was measured with the Bradford method. Proteins were denatured by heating at $95^{\circ} \mathrm{C}$ for $10 \mathrm{~min}$. Equal amounts of protein $(30 \mu \mathrm{g})$ from each sample were loaded onto acrylamide gels and separated by SDS-PAGE, and protein from the gel was transferred onto a nitrocellulose membrane. Membranes were incubated overnight at $4^{\circ} \mathrm{C}$ with rabbit anti-pSTAT3-Tyr705 and rabbit anti-STAT3 (dilution 1:1,000; Cell Signaling). Monoclonal mouse antirabbit GAPDH (dilution 1:2,000,000, Fitzgerald Industries) was used as a loading control. The blots were analyzed using the LICOR Odyssey Infrared Imaging System, and images were acquired using Adobe Photoshop CS4 software.

\section{Statistical analysis}

Statistical analysis was performed with Statistical Package for Social Sciences (SPSS 17.0 Software). Prenatal data were analyzed using the Mann-Whitney test. All postnatal data were analyzed using the one-way analysis of variance (ANOVA) test, followed by post-hoc comparisons using LSD correction. Multivariate testing was performed to test the interaction between birth and asphyxia. Results are presented as means + SEM and $p$-values $\leq 0.05$ were considered statistically significant.

\section{Results}

The impact on the cytokine expression of FA prenatally and in combination with a subsequent PA insult postnatally was assessed over a longitudinal time pattern until P7 (Figure 1). Both FA and PA induced acute cytokine changes in the brain. From P3 onwards, no significant differences were found in mRNA levels for any of the cytokines or receptors compared with control levels (data not shown).

\section{Acute downregulation of IL-1 $\beta$, TNF- $\alpha$ and IL-10 mRNA levels but increased IL- 6 mRNA and IL-10 protein expression occurred $96 \mathrm{~h}$ after fetal asphyxia}

Prenatally, FA induced an acute downregulation of IL-1 $\beta$ at $2 \mathrm{~h}$ (Figure 2A; $p=0.008$ ) and TNF- $\alpha$ at $6 \mathrm{~h}$ (Figure 2B; $p=0.05)$ compared with respective controls. The antiinflammatory cytokine IL-10 followed the same pattern as the acute inflammatory response of IL-1 $\beta$ and TNF- $\alpha$, with decreased IL-10 mRNA levels at $12 \mathrm{~h}$ after FA (Figure 2C; $p=0.02)$. In contrast to the decreased levels of the other cytokines measured in this study, IL-6 mRNA levels were elevated $96 \mathrm{~h}$ after FA compared with controls (Figure 2D; $p=0.03)$. All receptors for indicated cytokines showed mainly an elevation in mRNA levels after FA, mostly at time points after their respective cytokine response (data not shown).

Protein expression of TNF- $\alpha$, IL-10 and IL- 6 was determined at 6, 12 and $96 \mathrm{~h}$ after FA. CBA analysis revealed increased IL- 6 levels at $6 \mathrm{~h}$ post FA, although this was not significant (Figure 3B; $p=0.08$ ). IL-10 levels, however, were significantly increased at $96 \mathrm{~h}$ after FA compared with control levels (Figure 3C; $p=0.04$ ).

Since phosphorylated signal transducer and activator of transcription (STAT)-3 plays a role in post-ischemic brain damage [20] and all the cytokines that we measured can mediate their effects through pSTAT3 signaling, we measured the amount of pSTAT3 in control and FA brains. We could not find any significant changes in pSTAT3/ STAT3 levels at 6,12 or $96 \mathrm{~h}$ post FA (Figure 3D).

\section{An asphyctic insult acutely downregulates the proinflammatory response $2 \mathrm{~h}$ after birth}

Postnatally, IL-1 $\beta$, TNF- $\alpha$ and IL-6 mRNA levels decreased $2 \mathrm{~h}$ after birth in all experimental groups compared with control levels (Figure 4A-C).

To investigate if the decrease in proinflammatory cytokines $2 \mathrm{~h}$ after birth was attributable to the effect of birth itself or if it was specifically due to asphyxia, we compared cytokine levels from control E21 animals with control P0 animals ( $2 \mathrm{~h}$ after birth). Comparisons revealed that IL- $1 \beta$ and IL-10 decreased because of birth (Figure 5A and B; $p<0.01$ and $p<0.001$, respectively). mRNA levels for TNF- $\alpha$ and IL-6, however, did not differ between E21 and P0 animals [(Figure 5C and D); $p=0.12$ and $p=0.47$, respectively)]. Hence, we studied the mRNA levels of the housekeeping genes to assess if the decrease in IL-1 $\beta$ and IL-10 was attributable to a more general downregulation of the cellular response. Figure 5E shows that the housekeeping genes increased $2 \mathrm{~h}$ after birth in comparison with the E21 animals (left panel; $p<0.001$ ). Moreover, the housekeeping genes were not affected by an asphyctic insult (Figure $5 \mathrm{E}$, right panel). These results indicate that IL-1 $\beta$ and IL-10 decrease because of the birth process and that this response is specific for these cytokines. However, because IL-1 $\beta$ levels were even lower in animals that experienced an asphyctic insult, we assessed whether a synergic effect between birth and asphyxia was present. Surprisingly, multivariate testing between prenatal (E21) and postnatal (P0, $2 \mathrm{~h}$ after birth) animals revealed that the birth process interacts with the asphyctic insult for TNF $\alpha$, IL-6 and IL-10 $(p<0.05)$ but not for IL-1 $\beta$.

Although no changes in protein expression could be observed $2 \mathrm{~h}$ after birth (data not shown), the 


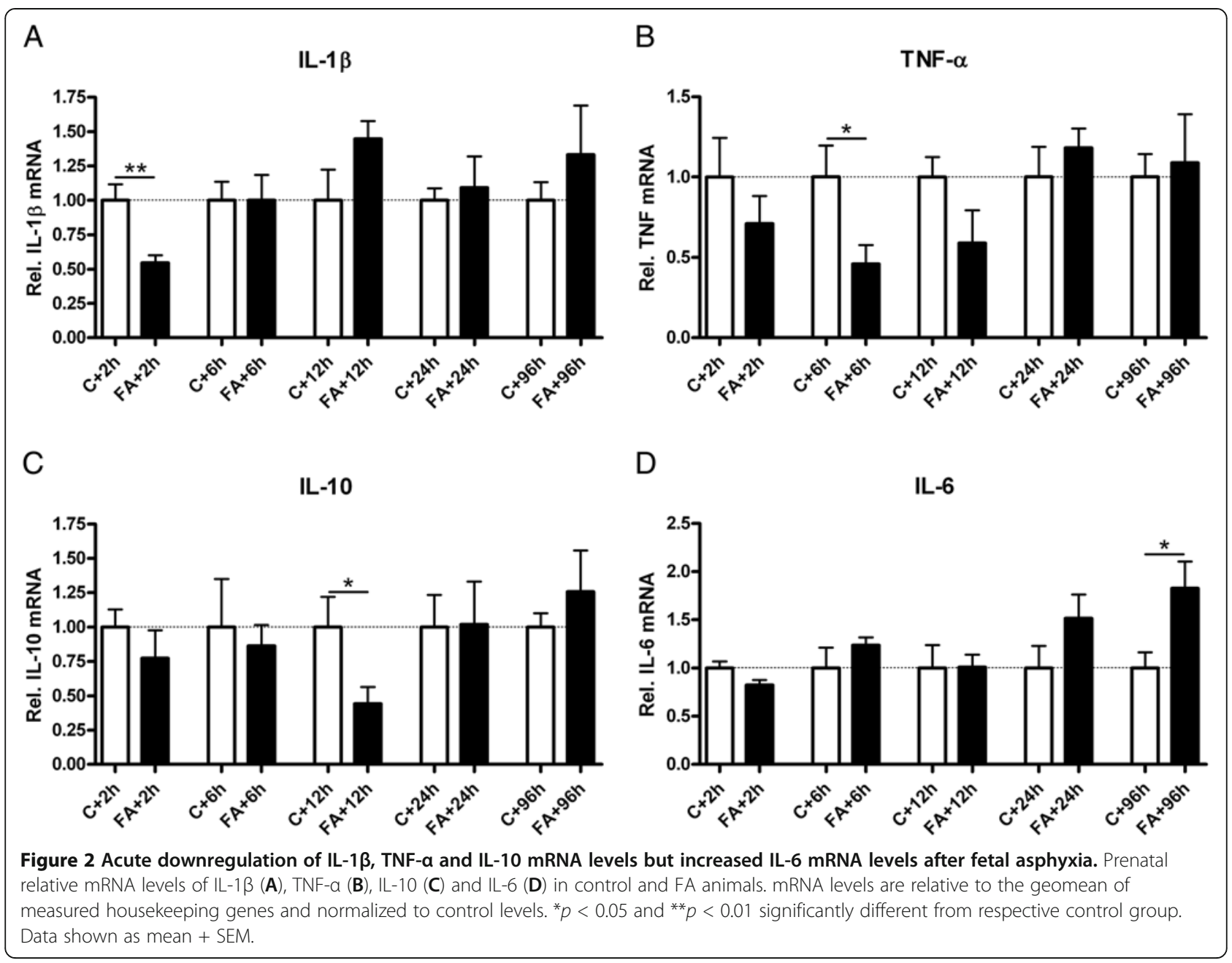

downregulation in cytokine mRNA levels did lead to decreased levels in pSTAT3/STAT3 $2 \mathrm{~h}$ after birth in all experimental groups (Figure 4E; $p<0.05$ ).

IL-10 and IL-6 mRNA levels are increased after perinatal asphyxia but attenuated in FA preconditioned animals Postnatally, IL-10 dissociated from the observed proinflammatory response with increased mRNA levels $2 \mathrm{~h}$ and $6 \mathrm{~h}$ after the PA insult. This effect was attenuated in the preconditioned animals (FA-PA group) (Figure 4D; $p<0.001)$. Interestingly, at $6 \mathrm{~h}$ and $12 \mathrm{~h}$ after birth an IL-6 mRNA profile similar to that for IL-10 was observed. More specifically, at $6 \mathrm{~h}$ IL-6 mRNA levels were reaching almost statistical significance in animals previously exposed to PA (Figure $4 C ; p=0.06$ ). Animals that were also exposed to the FA preconditioning stimulus (FA-PA group), however, showed baseline IL-6 mRNA levels (Figure $4 \mathrm{C} ; p=0.05$ for PA vs. FA-PA). This effect was expressed even more strongly at $12 \mathrm{~h}$ with increased IL-6 mRNA in PA animals (Figure 4C; $p<0.001)$ and baseline IL-6 mRNA levels in preconditioned animals (Figure 4C; $p<0.001$ for PA vs. FA-PA).

Despite the higher mRNA levels for IL-10 and IL-6 after PA, we could not find any significant changes in protein expression (data not shown). Surprisingly, at $12 \mathrm{~h}$ after PA the pSTAT3/STAT3 levels were decreased $(p<0.01)$, while FA-PA animals revealed comparable levels as control animals $(p<0.01$; Figure 4E).

\section{Diverse localization of measured cytokines in P7 brains}

Immunohistochemical stainings of IL-10, IL-6, IL-1 $\beta$ and TNF- $\alpha$ were performed to localize the cytokines in P7 rat brains. We observed that IL-1 $\beta$ is expressed in both the nucleus and cytosol (Figure 6A). IL-10 and IL-6 are mainly expressed in the nucleus (Figure 6B-C), while TNF- $\alpha$ is localized in the cytosol (Figure 6D). All cytokines also seemed to be expressed extracellular.

\section{Discussion}

In this study, we aimed to elucidate the inflammatory cytokine profile in response to global fetal and perinatal 

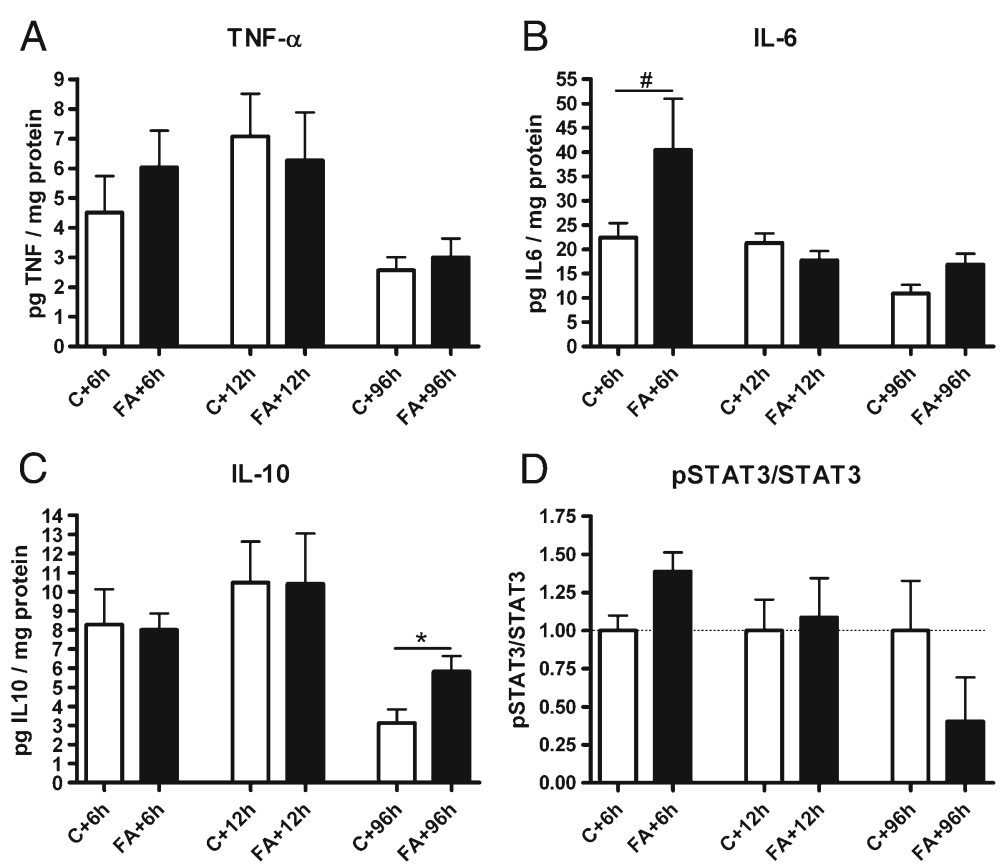

Figure 3 Increased IL-10 protein expression at 96 h post FA. Prenatal protein concentrations of TNF-a (A), IL-6 (B) and IL-10 (C) expressed in $\mathrm{pg} / \mathrm{mg}$ protein in control and FA animals. Relative protein expression of pSTAT3/STAT3 normalized to GAPDH and to respective control levels (D). \# $0.08<p<0.05 ;{ }^{*} p<0.05$ significantly different from respective control group. Data shown as mean + SEM.

asphyxia. Moreover, we investigated whether pro- and antiinflammatory cytokines played a role in the fetal induction of endogenous neuroprotection against PA injury. Prenatally, a time-dependent cytokine profile was observed after FA with acute downregulation of IL-1 $\beta$, TNF- $\alpha$ and IL-10 mRNA levels. At $96 \mathrm{~h}$ post FA, immediately before birth, IL-6 mRNA and IL-10 protein expression were increased. Postnatally, PA rats showed higher IL-10 and IL-6 mRNA levels after PA than control rats. Moreover, in FA preconditioned rats this effect was attenuated, showing an inflammatory phenotype similar to control animals.

Cytokines have been demonstrated to play an important role in the brain response to asphyxia. Moreover, they have been implicated in playing a protective role in the induction of ischemic tolerance $[13,16]$. The exact role of these cytokines and the time pattern of their expression have, however, not been elucidated yet. In human studies, IL-1 $\beta$, IL- 6 and TNF- $\alpha$ have been found to be upregulated in CSF of asphyxiated newborns compared with control neonates $[9,21]$. In these studies, CSF sampling was performed at only one time point ( $24 \mathrm{~h}$ and $48 \mathrm{~h}$ respectively) after birth. More time points are included in experimental models of focal asphyxia. These models are mainly based on the Rice-Vannucci model [22], where P7 rats are exposed to unilateral carotid artery occlusion, followed by a period of systemic hypoxia. Although these models are widely used to investigate the mechanisms involved in PA, they miss the transitional physiology from intrauterine to extrauterine life. The birth process itself is a physiologically unique period, with specific hormonal changes priming the fetus to be born [23]. This aspect was covered by the model used in our study as we awaited the vaginal delivery of the first pup so that the physiological conditions that occur during labor would be mimicked.

One aim of our study was to investigate the inflammatory mechanisms in global asphyxia. To the best of our knowledge, the role of cytokines in preconditioning during the fetal period has not been studied before. Therefore, we explored the impact of 30-min sublethal global fetal asphyxia on the levels of IL-1 $\beta$, TNF- $\alpha$, IL-10 and IL- 6 .

A time-dependent cytokine response after FA was observed prenatally. This response started $2 \mathrm{~h}$ after FA with decreased IL-1 $\beta$ mRNA levels, followed by a drop in TNF- $\alpha$ mRNA levels at $6 \mathrm{~h}$ post FA. Both IL-1 $\beta$ and TNF- $\alpha$ are key mediators of the acute inflammatory response [24] and have been shown to be upregulated after global cerebral hypoxia-ischemia in adult and neonatal rats $[12,25,26]$. Important differences between the addressed studies and our observations include the nature and the time point of the asphyctic insult. The FA that we induced is only a sublethal insult with no fetal losses or morbidity in adulthood [4]. Additionally, we induced the stimulus prenatally, and it has been suggested that the fetal brain is less reactive to inflammatory reactions than a mature brain [26].

The antiinflammatory cytokine also showed decreased mRNA levels at $12 \mathrm{~h}$ after FA. IL-10 is an important antiinflammatory mediator of the immune response and 


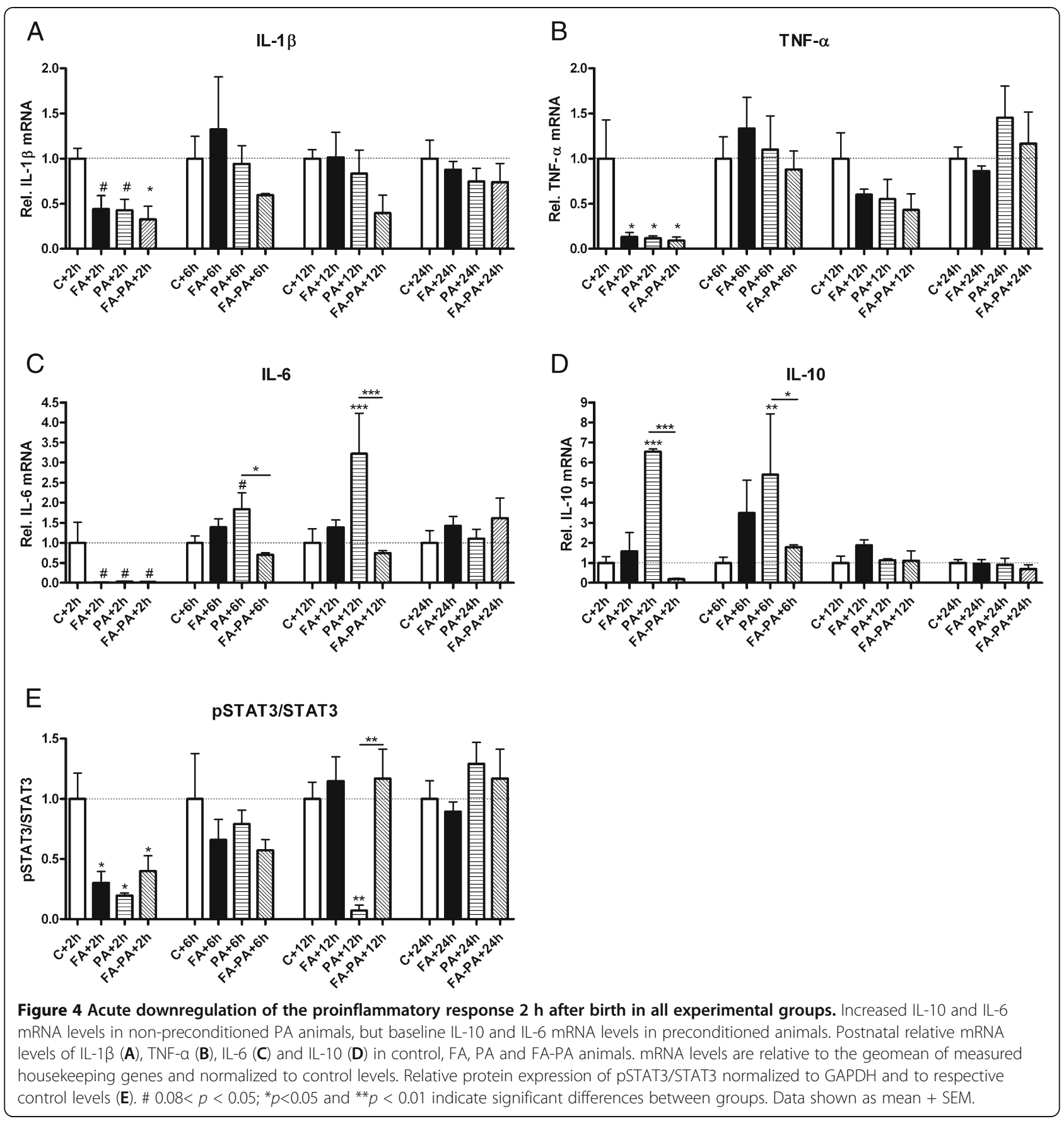

has been shown to be both upregulated [27] and downregulated [28] after an hypoxic-ischemic insult. In addition, IL-10 prevents neurodegeneration by protecting neurons through activation of PI-3-kinase and STAT-3 pathways $[29,30]$. Interestingly, at $96 \mathrm{~h}$ after FA protein expression of IL-10 was increased together with increased IL- 6 mRNA levels. It is known that IL- 6 is secreted together with the antiinflammatory cytokine IL-10 [21,31], and IL-6 is a pleiotropic cytokine with both pro- and antiinflammatory effects in the injured brain [32,33]. IL-6 has been shown to be expressed more on neurons in response to ischemia, promoting neuronal survival and development [34]. Furthermore, a study by Yamashita and coworkers showed that endogenous IL-6 plays a critical role in preventing apoptosis of damaged neurons in the acute phase of cerebral ischemia in mice [35].

Taken together, these data indicate that FA induces acute changes in the cytokine response. Since IL-6 


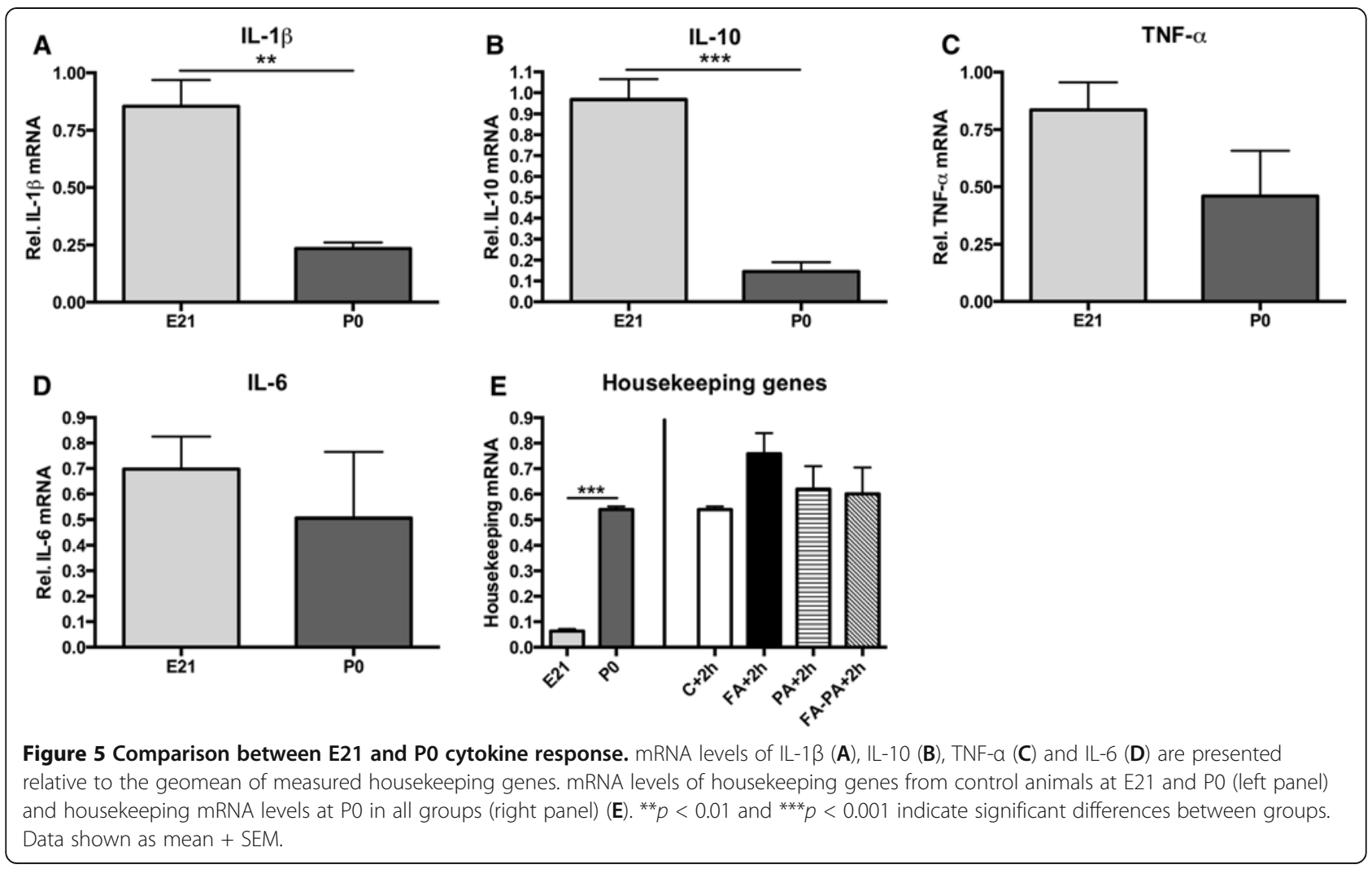

mRNA and IL-10 protein levels are increased at $96 \mathrm{~h}$ post FA, the time point immediately before birth, these cytokines might be involved in inducing neuroprotection.

The second aim of our study was to investigate whether the changes in cytokine response observed because of FA have any protective effect against a subsequent more severe PA insult. Our data showed decreased mRNA levels of the proinflammatory cytokines (IL-1 $\beta$, TNF- $\alpha$ and IL-6) $2 \mathrm{~h}$ after birth in all experimental groups compared with control animals. Moreover, pSTAT3/STAT3 levels were decreased, indicating a downregulation in proinflammatory response. This decrease in cytokine levels is in accordance with a study from Ashdown et al., who observed decreased IL-1 $\beta$ and TNF- $\alpha$ protein and decreased IL-6 mRNA in the brain at $2 \mathrm{~h}$ after birth asphyxia [7]. They claimed that the downregulation in cytokine levels was due to global birth asphyxia itself and not to the C-section. Comparison of E21 and P0 control animals revealed that IL-1 $\beta$ and IL-10 levels decreased because of birth. Control levels of TNF- $\alpha$ and IL-6 did not show decreased levels due to birth. These are remarkable findings because studies have shown that the proinflammatory response is increased during the birth process [36]. Additionally, although IL-1 $\beta$ control levels decreased $2 \mathrm{~h}$ after birth, these levels were lower in the experimental groups than in the control groups, suggesting an interaction between the birth process and asphyxia. However, a synergic effect between birth and any asphyctic insult (FA and/or PA) was not observed for IL-1 $\beta$ but for the other cytokines. Hence, the drop in inflammatory cytokines $2 \mathrm{~h}$ after birth remains an interesting and important observation because focal asphyctic episodes have been associated with increased inflammation $[6,11,12,26]$. Studies indicate that endogenous production of glucocorticoids may play an important role in the suppression of specific cytokine

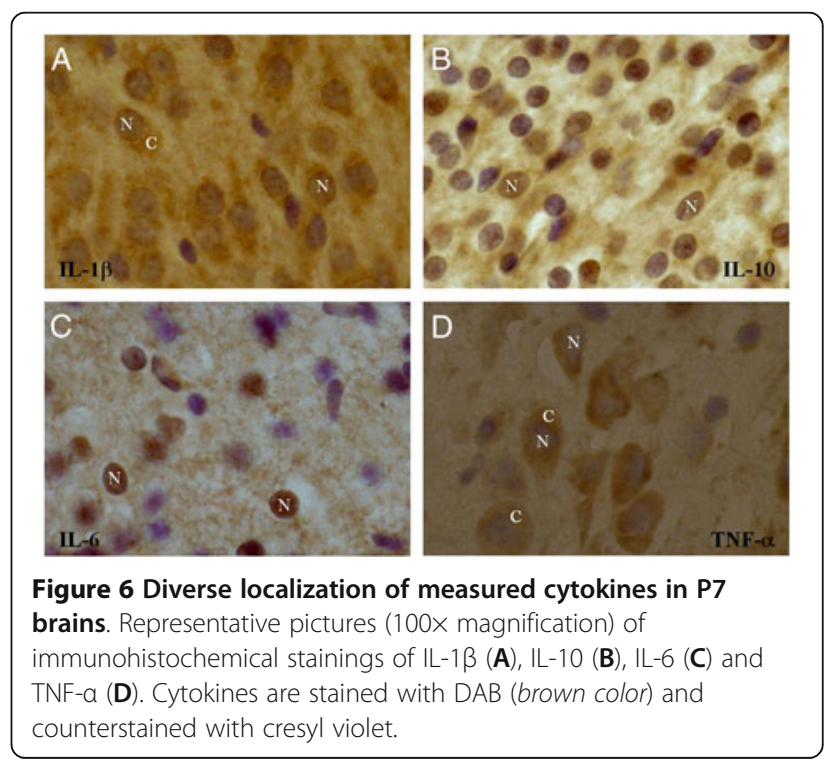


production and inflammation [37]. As it has been established that birth is associated with higher stress hormones, such as cortisol and catecholamines [38], and hypoxia induces an even higher catecholamine response in the fetus [39], we can assume that the animals that had experienced an asphyctic insult before had higher corticosteroid levels. Accordingly, these animals would be able to downregulate the proinflammatory response as a protective mechanism.

One of the main findings of our study is that IL-10 was highly expressed in asphyxiated animals $2 \mathrm{~h}$ after birth. Moreover, significantly elevated mRNA levels of IL- 6 were observed at $6 \mathrm{~h}$ and $12 \mathrm{~h}$ after PA. These data are comparable to the abundance of evidence indicating increased cytokine levels in the brain due to hypoxiaischemia $[6,11,12,26]$. Most importantly, a preconditioning effect was observed in both IL-10 and IL- 6 mRNA levels. So the increase in IL-10 and IL-6 mRNA caused by PA was attenuated and comparable to control levels in the preconditioned FA-PA animals. Studies have already demonstrated that inhibition of cytokine activity reduces excitotoxic brain injury in neonatal rats [11,40,41]. An important role for the cytokines IL-10 and IL-6 after global asphyxia is highlighted in our study. An IL-6 response to asphyxia has been correlated with higher mortality rates [21]. Therefore, the changes in IL-6 levels could indicate why FA preconditioned animals have a higher survival chance after PA compared with non-preconditioned animals. Although both human and experimental data show increased levels of IL-10 and IL- 6 after asphyctic injury $[9,11,12,28,31]$, the precise role of these cytokines in cerebral asphyxia has not been fully elucidated. Hence, further studies on the role of IL-10 and IL- 6 in the pathophysiology of global perinatal brain injury are warranted.

It has been shown that the post-ischemic inflammatory neuronal damage is amplified by the STAT signaling pathways [42,43]. Additionally, prevention of the postischemic STAT3 phosphorylation leads to significant neuroprotection and a decrease in neurological deficits [20]. Surprisingly, we found decreased pSTAT3 expression $12 \mathrm{~h}$ post PA, while preconditioned animals showed baseline pSTAT3 expression. We can assume that the downregulation in pSTAT3 levels is an attempt to promote neuronal survival since we are looking at the brains of surviving offspring.

\section{Conclusions}

In this study, we report important findings concerning the inflammatory mechanisms of global asphyctic brain damage and the role of inflammatory cytokines in the induction of neuroprotection against perinatal asphyctic injury. Consistent with our hypothesis, we demonstrated that FA induces time-dependent cytokine changes with acute downregulation of IL-1 $\beta$, TNF- $\alpha$ and IL-10 mRNA, followed by increased IL- 6 mRNA and IL-10 protein expression. Importantly, these prenatal changes downregulate the cytokine response when combined with a global asphyctic insult at birth. Although we did not observe any changes in cytokine levels from $24 \mathrm{~h}$ after PA, we previously showed that PA induces astrogliosis and apoptosis at 7 days post PA, which will lead to motor and memory deficits in adulthood [4]. Therefore, gaining more insights into the inflammatory pathways of IL- 6 and IL-10 acutely after global asphyxia may have significant implications for preventing or modulating the permanent effects of postasphyctic encephalopathy.

\section{Competing interests}

There are no competing interests for this manuscript.

\section{Authors' contributions}

EV performed all animal work, cytokine mRNA/protein measurements, Western blots and stainings, performed statistical analysis and wrote the manuscript. ES assisted with the animal work and edited the paper. MN assisted with the animal work and all cytokine measurements. JSHV, PM, BWK and AWDG provided critical guidance and worked on the manuscript. All authors read and approved the final manuscript.

\section{Acknowledgements}

The authors would like to thank Tammy Oth, Jana Slechter and Annelies Thijssen for technical support. Special gratitude is offered to Tomasz Brudek and Bente Pakkenberg for providing the cytokine antibodies for immunohistochemistry.

\section{Author details}

'Department of Pediatrics Division of Neonatology, Maastricht University Medical Center, School for Oncology and Developmental Biology Maastricht (GROW), Maastricht, AZ 6202, The Netherlands. 'Department of Neuropsychology Division Neuroscience, Maastricht University, School of Mental Health and Neuroscience (MHeNS), Maastricht, MD 6200, The Netherlands. ${ }^{3}$ Child Neurology, Maastricht University Medical Center, Maastricht, AZ 6202, The Netherlands.

Received: 2 April 2012 Accepted: 10 January 2013

Published: 26 January 2013

\section{References}

1. Low JA: Determining the contribution of asphyxia to brain damage in the neonate. J Obstet Gynaecol Res 2004, 30:276-286.

2. Berger R, Garnier Y: Pathophysiology of perinatal brain damage. Brain Res Brain Res Rev 1999, 30:107-134.

3. Thoresen M: Hypothermia after perinatal asphyxia: selection for treatment and cooling protocol. J Pediatr 2011, 158:45-49.

4. Strackx E, Van den Hove DL, Prickaerts J, Zimmermann L, Steinbusch HW, Blanco CE, Gavilanes AW, Vles JS: Fetal asphyctic preconditioning protects against perinatal asphyxia-induced behavioral consequences in adulthood. Behav Brain Res 2010, 208:351-343.

5. Strackx E, Zoer B, Van den Hove D, Steinbusch H, Steinbusch H, Blanco C, Vles JS, Villamor E, Gavilanes AW: Brain apoptosis and carotid artery reactivity in fetal asphyctic preconditioning. Front Biosci (Schol Ed) 2010, 2:781-790.

6. Maslinska D, Laure-Kamionowska M, Kaliszek A, Makarewicz D: Proinflammatory cytokines in injured rat brain following perinatal asphyxia. Folia Neuropathol 2002, 40:177-182.

7. Ashdown H, Joita S, Luheshi GN, Boksa P: Acute brain cytokine responses after global birth hypoxia in the rat. J Neurosci Res 2008, 86:3401-3409.

8. Denes A, Thornton P, Rothwell NJ, Allan SM: Inflammation and brain injury: acute cerebral ischaemia, peripheral and central inflammation. Brain Behav Immun 2010, 24:708-723. 
9. Silveira RC, Procianoy RS: Interleukin-6 and tumor necrosis factor-alpha levels in plasma and cerebrospinal fluid of term newborn infants with hypoxic-ischemic encephalopathy. J Pediatr 2003, 143:625-629.

10. Okazaki K, Nishida A, Kato M, Kozawa K, Uga N, Kimura H: Elevation of cytokine concentrations in asphyxiated neonates. Biol Neonate 2006, 89:183-189.

11. Hagberg H, Gilland E, Bona E, Hanson LA, Hahin-Zoric M, Blennow M, Holst M, McRae A, Soder O: Enhanced expression of interleukin (IL)-1 and IL-6 messenger RNA and bioactive protein after hypoxia-ischemia in neonatal rats. Pediatr Res 1996, 40:603-609.

12. Szaflarski J, Burtrum D, Silverstein FS: Cerebral hypoxia-ischemia stimulates cytokine gene expression in perinatal rats. Stroke 1995, 26:1093-1100.

13. Shin JA, Park EM, Choi JS, Seo SM, Kang JL, Lee KE, Cho S: Ischemic preconditioning-induced neuroprotection is associated with differential expression of IL-1 beta and IL-1 receptor antagonist in the ischemic cortex. J Neuroimmunol 2009, 217:14-19.

14. Pradillo JM, Fernandez-Lopez D, Garcia-Yebenes I, Sobrado M, Hurtado O, Moro MA, Lizasoain I: Toll-like receptor 4 is involved in neuroprotection afforded by ischemic preconditioning. J Neurochem 2009, 109:287-294.

15. Feng Z, Davis DP, Sasik R, Patel HH, Drummond JC, Patel PM: Pathway and gene ontology based analysis of gene expression in a rat model of cerebral ischemic tolerance. Brain Res 2007, 1177:103-123.

16. Yin W, Signore AP, Iwai M, Cao G, Gao Y, Johnnides MJ, Hickey RW, Chen J: Preconditioning suppresses inflammation in neonatal hypoxic ischemia via Akt activation. Stroke 2007, 38:1017-1024.

17. Strackx E, Van den Hove DL, Prickaerts J, Zimmermann L, Steinbusch HW, Blanco CE, Gavilanes AW, Vles JS: Fetal asphyctic preconditioning protects against perinatal asphyxia-induced behavioral consequences in adulthood. Behav Brain Res 2010, 208:343-351.

18. Strackx E, Zoer B, Van den Hove D, Steinbusch H, Blanco C, Vles JS, Villamor E, Gavilanes AW: Brain apoptosis and carotid artery reactivity in fetal asphyctic preconditioning. Front Biosci (Schol Ed) 2010, 2:781-790.

19. Soldan SS: Alvarez Retuerto Al, Sicotte NL, Voskuhl RR: Dysregulation of IL-10 and IL-12p40 in secondary progressive multiple sclerosis. J Neuroimmunol 2004, 146:209-215.

20. Satriotomo I, Bowen KK, Vemuganti R: JAK2 and STAT3 activation contributes to neuronal damage following transient focal cerebral ischemia. J Neurochem 2006, 98:1353-1368.

21. Aly H, Khashaba MT, El-Ayouty M, El-Sayed O, Hasanein BM: IL-1 beta, IL-6 and TNF-alpha and outcomes of neonatal hypoxic ischemic encephalopathy. Brain Dev 2006, 28:178-182.

22. Vannucci RC, Vannucci SJ: A model of perinatal hypoxic-ischemic brain damage. Ann N Y Acad Sci 1997, 835:234-249.

23. Tyzio R, Cossart R, Khalilov I, Minlebaev M, Hubner CA, Represa A, Ben-Ari Y, Khazipov R: Maternal oxytocin triggers a transient inhibitory switch in GABA signaling in the fetal brain during delivery. Science 2006, 314:1788-1792.

24. Chao CC, Hu S, Ehrlich L, Peterson PK: Interleukin-1 and tumor necrosis factor-alpha synergistically mediate neurotoxicity: involvement of nitric oxide and of N-methyl-D-aspartate receptors. Brain Behav Immun 1995, 9:355-365.

25. Haqqani AS, Nesic M, Preston E, Baumann E, Kelly J, Stanimirovic D: Characterization of vascular protein expression patterns in cerebral ischemia/reperfusion using laser capture microdissection and ICAT-nanoLC-MS/MS. FASEB J 2005, 19:1809-1821.

26. Bona E, Andersson AL, Blomgren K, Gilland E, Puka-Sundvall M, Gustafson K, Hagberg $\mathrm{H}$ : Chemokine and inflammatory cell response to hypoxiaischemia in immature rats. Pediatr Res 1999, 45:500-509.

27. Brochu ME, Girard S, Lavoie K, Sebire G: Developmental regulation of the neuroinflammatory responses to LPS and/or hypoxia-ischemia between preterm and term neonates: An experimental study. J Neuroinflammation 2011, 8:55

28. Kremlev SG, Roberts RL, Palmer C: Minocycline modulates chemokine receptors but not interleukin-10 mRNA expression in hypoxic-ischemic neonatal rat brain. J Neurosci Res 2007, 85:2450-2459.

29. Park KW, Lee HG, Jin BK, Lee YB: Interleukin-10 endogenously expressed in microglia prevents lipopolysaccharide-induced neurodegeneration in the rat cerebral cortex in vivo. Exp Mol Med 2007, 39:812-819.

30. Sharma S, Yang B, Xi X, Grotta JC, Aronowski J, Savitz SI: IL-10 directly protects cortical neurons by activating PI-3 kinase and STAT-3 pathways. Brain Res 2011, 1373:189-194.
31. Martin-Ancel A, Garcia-Alix A, Pascual-Salcedo D, Cabanas F, Valcarce M, Quero J: Interleukin-6 in the cerebrospinal fluid after perinatal asphyxia is related to early and late neurological manifestations. Pediatrics 1997, 100:789-794.

32. Gadient RA, Otten UH: Interleukin-6 (IL-6)-a molecule with both beneficial and destructive potentials. Prog Neurobiol 1997, 52:379-390.

33. Suzuki S, Tanaka K, Suzuki N: Ambivalent aspects of interleukin- 6 in cerebral ischemia: inflammatory versus neurotrophic aspects. J Cereb Blood Flow Metab 2009, 29:464-479.

34. Jones SA, Horiuchi S, Topley N, Yamamoto N, Fuller GM: The soluble interleukin 6 receptor: mechanisms of production and implications in disease. FASEB J 2001, 15:43-58.

35. Yamashita T, Sawamoto K, Suzuki S, Suzuki N, Adachi K, Kawase T, Mihara M, Ohsugi Y, Abe K, Okano H: Blockade of interleukin-6 signaling aggravates ischemic cerebral damage in mice: possible involvement of Stat3 activation in the protection of neurons. J Neurochem 2005, 94:459-468.

36. Yektaei-Karin E, Moshfegh A, Lundahl J, Berggren V, Hansson LO, Marchini G: The stress of birth enhances in vitro spontaneous and IL-8-induced neutrophil chemotaxis in the human newborn. Pediatr Allergy Immunol 2007, 18:643-651.

37. Munck A, Guyre PM, Holbrook NJ: Physiological functions of glucocorticoids in stress and their relation to pharmacological actions. Endocr Rev 1984, 5:25-44

38. Wang $L$, Zhang $W$, Zhao $Y$ : The study of maternal and fetal plasma catecholamines levels during pregnancy and delivery. J Perinat Med 1999, 27:195-198.

39. Gulmezoglu AM, Mahomed K, Hofmeyr GJ, Nikodem VC, Kramer T: Fetal and maternal catecholamine levels at delivery. J Perinat Med 1996 24:687-691.

40. Martin D, Chinookoswong N, Miller G: The interleukin-1 receptor antagonist (rhlL-1 ra) protects against cerebral infarction in a rat model of hypoxia-ischemia. Exp Neurol 1994, 130:362-367.

41. Sun Y, Calvert JW, Zhang JH: Neonatal hypoxia/ischemia is associated with decreased inflammatory mediators after erythropoietin administration. Stroke 2005, 36:1672-1678.

42. O'Shea JJ, Gadina M, Schreiber RD: Cytokine signaling in 2002: new surprises in the Jak/Stat pathway. Cell 2002, 109(Suppl):S121-131.

43. Suzuki S, Tanaka K, Nogawa S, Dembo T, Kosakai A, Fukuuchi Y: Phosphorylation of signal transducer and activator of transcription-3 (Stat3) after focal cerebral ischemia in rats. Exp Neurol 2001, 170:63-71.

\section{doi:10.1186/1742-2094-10-14}

Cite this article as: Vlassaks et al:: Fetal asphyctic preconditioning modulates the acute cytokine response thereby protecting against perinatal asphyxia in neonatal rats. Journal of Neuroinflammation 2013 $10: 14$

\section{Submit your next manuscript to BioMed Central and take full advantage of:}

- Convenient online submission

- Thorough peer review

- No space constraints or color figure charges

- Immediate publication on acceptance

- Inclusion in PubMed, CAS, Scopus and Google Scholar

- Research which is freely available for redistribution 